\title{
Corrigendum
}

\section{Corrigendum to "Analysis of the Coupling Coefficient in Inductive Energy Transfer Systems"}

\author{
Rafael Mendes Duarte and Gordana Klaric Felic \\ The University of Melbourne, Parkville, VIC 3010, Australia \\ Correspondence should be addressed to Rafael Mendes Duarte; rmendesduarte@gmail.com \\ Received 14 December 2015; Accepted 16 February 2016
}

Copyright (c) 2016 R. Mendes Duarte and G. Klaric Felic. This is an open access article distributed under the Creative Commons Attribution License, which permits unrestricted use, distribution, and reproduction in any medium, provided the original work is properly cited.

In the paper titled "Analysis of the Coupling Coefficient in Inductive Energy Transfer Systems” [1], Equation (16) is the voltage drop across the secondary coil and is written as

$$
V_{1}=j w\left(I_{2} L_{2}+M I_{1}\right) .
$$

However, the correct expression is

$$
V_{2}=j w\left(I_{2} L_{2}+M I_{1}\right) .
$$

In addition, the mutual inductance $M$ in Equation (18) should be squared, resulting in

$$
V_{1}=j w I_{1}\left(L_{1}-\frac{M^{2}}{L_{2}}\right) .
$$

As a result, the mutual inductance in Equation (19) must also be corrected, yielding

$$
L_{s}=L_{1}-\frac{M^{2}}{L_{2}} \text {. }
$$

Finally, the mutual inductance measured when the secondary coil is shorted, shown in Equation (21), should be written as

$$
M=\sqrt{L_{2}\left(L_{1}-L_{s}\right)} .
$$

Now, the substitution of Equation (21) in Equation (2) of [1] results in the expression given by Equation (22).

\section{References}

[1] R. Mendes Duarte and G. Klaric Felic, "Analysis of the coupling coefficient in inductive energy transfer systems," Active and Passive Electronic Components, vol. 2014, Article ID 951624, 6 pages, 2014. 


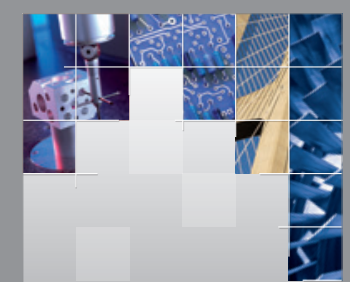

\section{Enfincering}
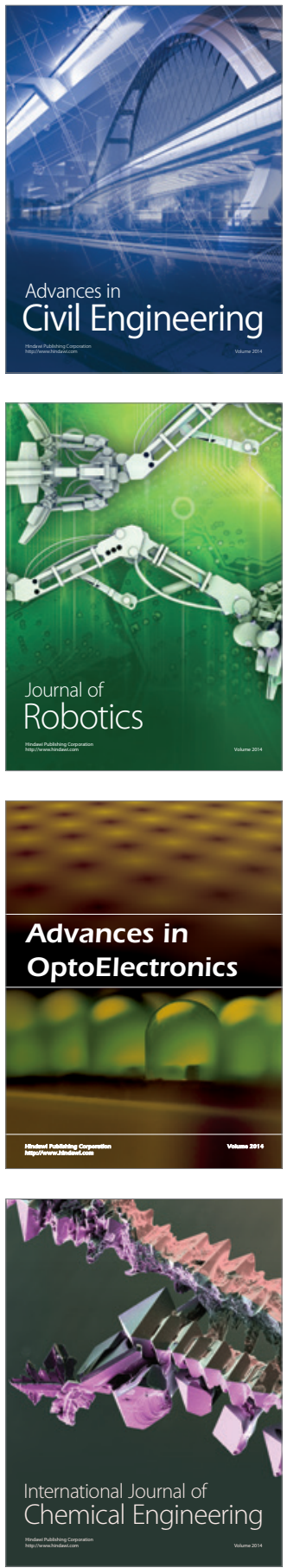

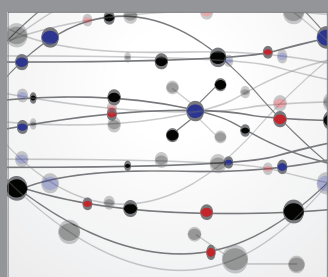

The Scientific World Journal

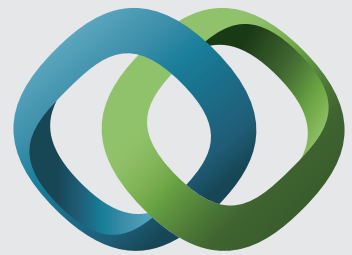

\section{Hindawi}

Submit your manuscripts at

http://www.hindawi.com
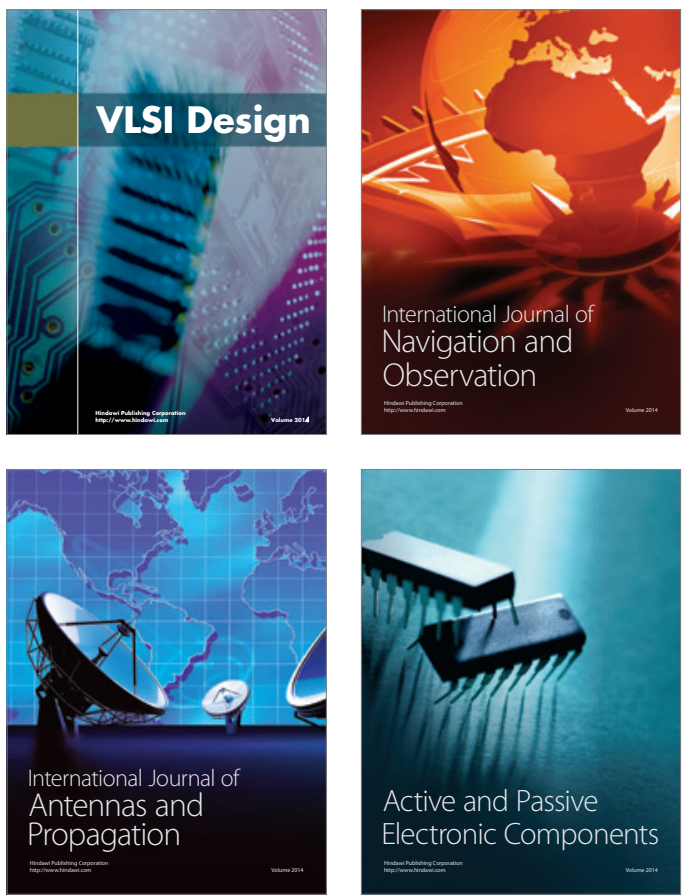
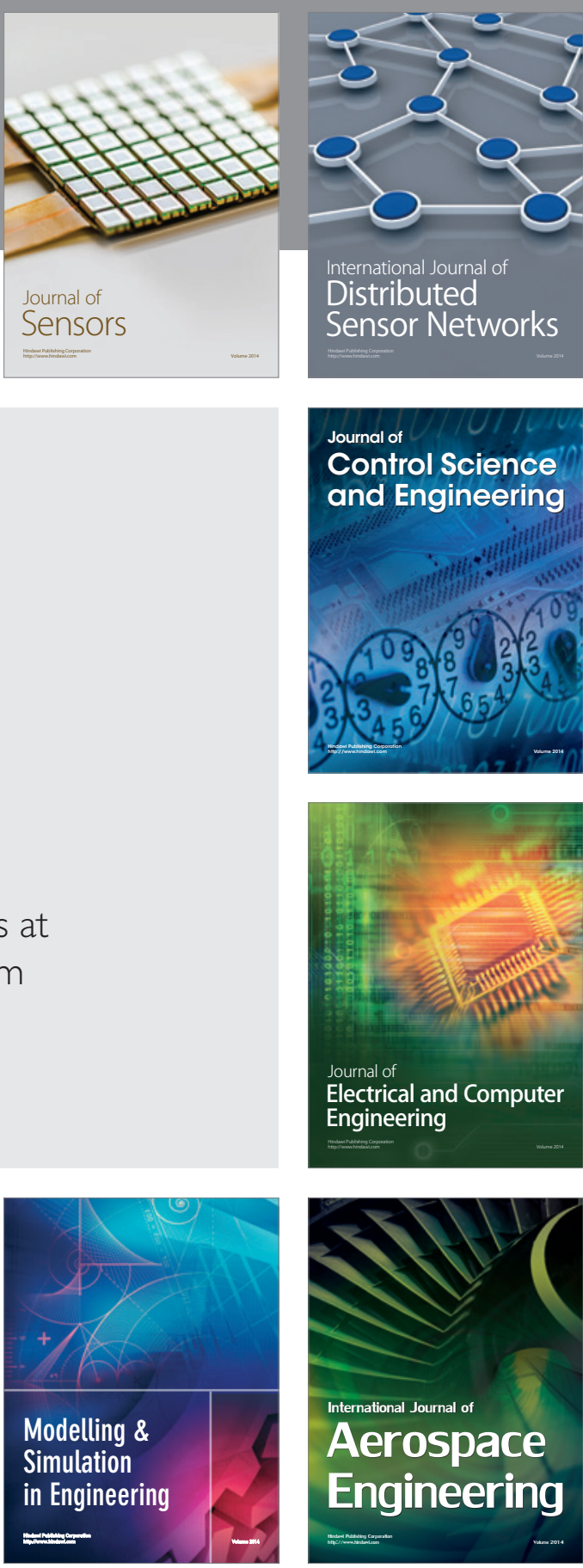

International Journal of

Distributed

Sensor Networks

Journal of

Control Science

and Engineering
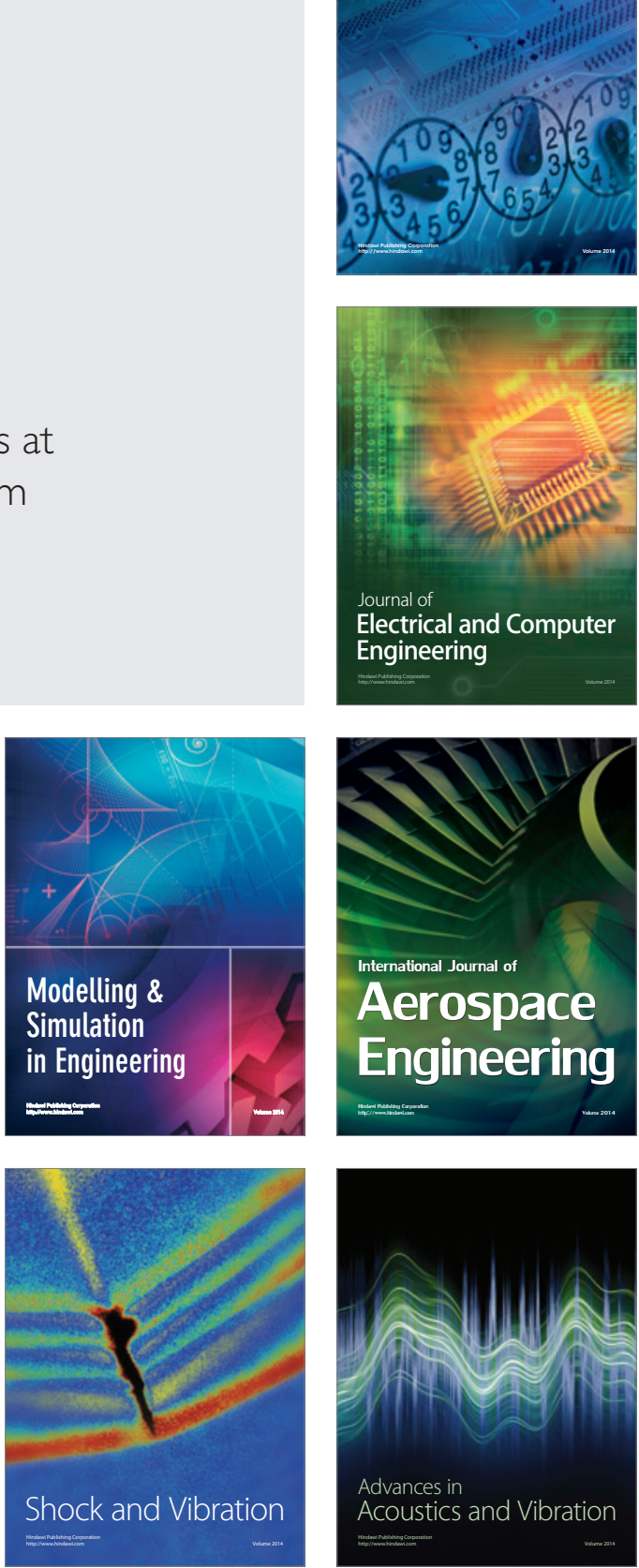